\section{Pedro Cerrillo}

Doctor en Filología Hispánica y Catedrático de Didáctica de la Lengua y la Literatura de la Universidad de Castilla-La Mancha. Líneas de investigación: «LIJ y educación literaria» y «Lírica popular infantil». Dirige un proyecto de investigación, financiado por el $\mathrm{M}^{\circ}$ de Educación, sobre «Censuras y LIJ en el siglo XX en los países del ámbito hispanoamericano». Ha publicado diversas monografías y más de un centenar de artículos en revistas científicas norteamericanas, portuguesas, brasileñas o eslovenas.
Literatura infantil y educación en el exilio español en México

PEDRO C. CERRILLO

\title{
Literatura infantil y educación en el exilio español en México
}

\author{
PEDRO C. CERRILLO \\ Universidad de Castilla-La Mancha
}

\section{RESUMEN}

La Guerra Civil (1936-1939) española supuso la llegada de miles de españoles (muchos de ellos republicanos) a México, entre los cuales se encontraban artistas que difundieron la cultura continuando los proyectos peninsulares e iniciando nuevas relaciones con América. Desde entonces, los títulos de obras y autores de Literatura infantil son numerosos. Este artículo repasa la labor del exilio español en México con los textos destinados a los más pequeños.

Palabras clave: Literatura Infantil y Juvenil, Exilio, México.

\section{ABSTRACT}

The Spanish Civil War (1936-1939) marked the arrival of thousands of Spanish people (many Republicans) to Mexico, some of them were artists who spread the culture peninsular continuing projects and starting new relations with America. Thence, book's titles and authors of children's literature are numerous. This article reviews the work of the Spanish exile in with the texts for the little ones.

Keywords: Children's and Youth Literature, Exile, Mexico.

El exiliado es, casi siempre, una persona que debe abandonar sus raíces e iniciar la nada fácil tarea de plantar unas nuevas en otro lugar, a menudo muy distinto y lejano del suyo originario. A la cotidiana tarea de procurarse trabajo, alimento y vivienda, deberá unir la de indagar en una sociedad y en una cultura que no son las suyas, en busca de algunos puntos de referencia que le permitan volver a tener proyectos en el seno de esa nueva sociedad. Al margen de sus sentimientos e ideas, las señas de identidad del exiliado quedan reducidas a los recuerdos de una tradición cultural truncada.

\section{El exilio español tras la Guerra Civil}

Entre febrero y finales de abril de 1939, medio millón de españoles salieron de su país, casi el $90 \%$ rumbo a Francia y un 10\% hacia el norte de África (Ruiz-Funes 40). Algunos murieron ese mismo año en los campos de concentración del sur de Francia y de Alemania; algunos más regresaron a España y la mayoría se marchó a América (Santo Domingo, Argentina y, sobre todo, México).

El éxodo se inició en toda regla cuando los sublevados - ganada la cruel guerra civil que ellos habían provocado- extremaron la represión y la venganza, iniciándose un largo periodo en el que fueron constantes las delaciones, las torturas, los asesinatos, los «juicios sumarísimos», la cárcel interminable, la represión, la persecución implacable. El éxodo fue entonces la única vía de salida que tenían los perdedores porque, de algún modo, era la manera más segura de continuar vivos. Pero con el éxodo empezó la fractura de la educación y la literatura - también de la Literatura Infantil y Juvenil (en adelante LIJ) - que se hacían en España hasta ese momento. 
En los españoles republicanos que iniciaron la aventura del exilio en los últimos momentos de la Guerra Civil, o nada más terminada esta, se avivó el convencimiento de que el suyo era un destierro transitorio y que, pasado no mucho tiempo, volverían a una España leal y legítima; ese convencimiento, día a día, fue chocando contra el muro de una dictadura que duró, en contra de su inicial convencimiento, casi cuarenta años. Pasado ese tiempo, ya no era posible el retorno: había transcurrido la mejor parte de unas vidas que ya eran mexicanas, norteamericanas, dominicanas, cubanas, argentinas, venezolanas, uruguayas, francesas,... Algunos habían muerto. Y, en casi todos los casos, sus raíces españolas eran solo los recuerdos, muchos de ellos infantiles.

El desgarro de los exiliados españoles republicanos era doble: al hecho mismo del destierro se le unía el sentimiento de saberse perdedores, aun estando en posesión de la legítima razón política, que habían defendido con denuedo. Cada cual tuvo que buscar, a menudo desesperadamente, un nuevo lugar en el que reiniciar su vida en la paz y la libertad que en su país les habían arrebatado, pasando, en bastantes casos, la humillación de unos campos de concentración crueles e inhumanos, como los franceses. Ya en los países de acogida, los exiliados españoles quisieron mantener la conciencia de su resistencia antifranquista, lo que hizo que, en algunos casos, no se produjera la integración total del exiliado en el lugar en donde iniciaba una nueva vida, esperando cada día que la situación en España revirtiera al estado anterior al inicio del conflicto bélico. Algunos historiadores han coincidido al señalar que en la mayoría de aquellos exiliados se puede diferenciar un primer momento de desesperanza y fracaso, bastante largo en muchos de ellos, al que siguió otro momento de nostalgia de la patria abandonada, más sereno que el anterior (Albornoz 17).

México, nueva patria de millares de exiliados españoles

México, acogió a millares de refugiados republicanos españoles de una manera institucionalmente organizada, gracias a la valentía de un gran estadista, Lázaro Cárdenas, presidente de México desde 1934, quien no dudó en recibirlos con los honores de que

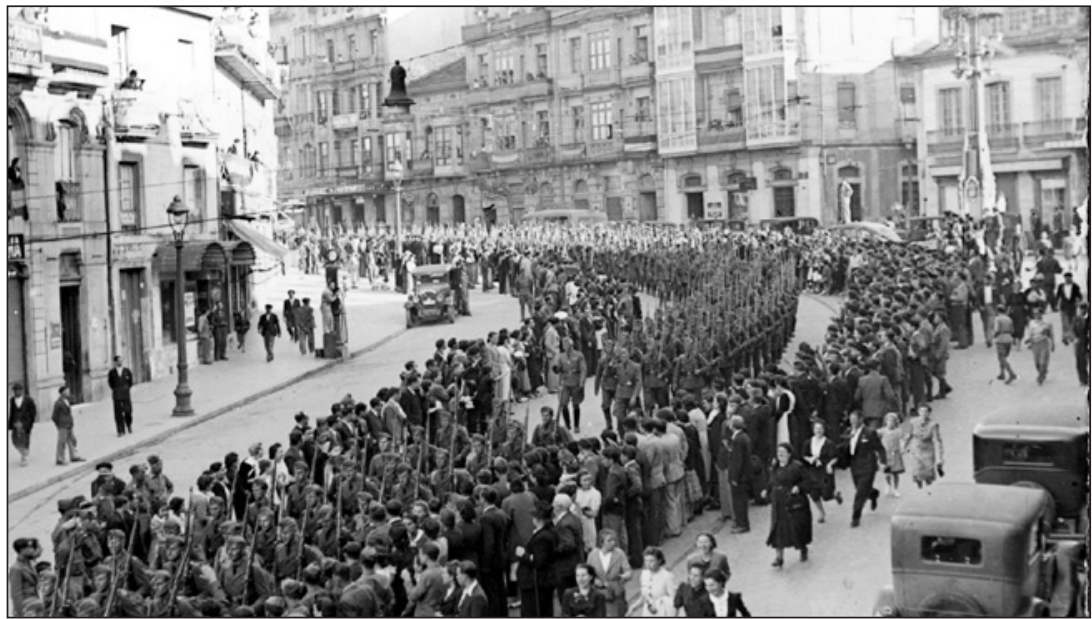

Guerra Civil española.

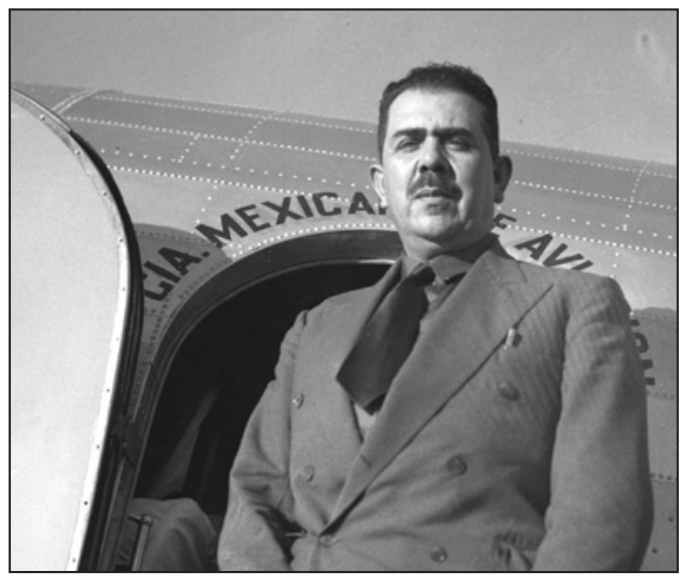

Lázaro Cárdenas.

eran portadores: en la guerra española la derrota no supuso ningún deshonor, ya que los vencedores eran los rebeldes que iniciaron la contienda. Cárdenas quiso hacer justicia a los republicanos españoles derrotados, ofreciéndoles tanto las garantías jurídicas que corresponden a asilados políticos en los estados de derecho, como sus simpatías por el propio proyecto, ya roto, de la $2^{a}$ República Española, haciendo posible que iniciaran una nueva vida en libertad, fuera cual fuera su origen, su procedencia o su adscripción política.

México ya había demostrado su simpatía por España en los años de la $2^{\text {a }}$ República: en 1931, al poco de proclamarse la misma, el gobierno mexicano elevó a categoría de embajada la hasta entonces delegación mexicana en Madrid. A partir de entonces, las relaciones políticas y diplomáticas fueron muy fluidas e intensas, así como fructíferos los intercambios culturales. Durante aquellos años, en algunos casos incluso antes, y fruto de esas buenas re-
Literatura infantil y educación en el exilio español en México

PEDRO C. CERRILLO 


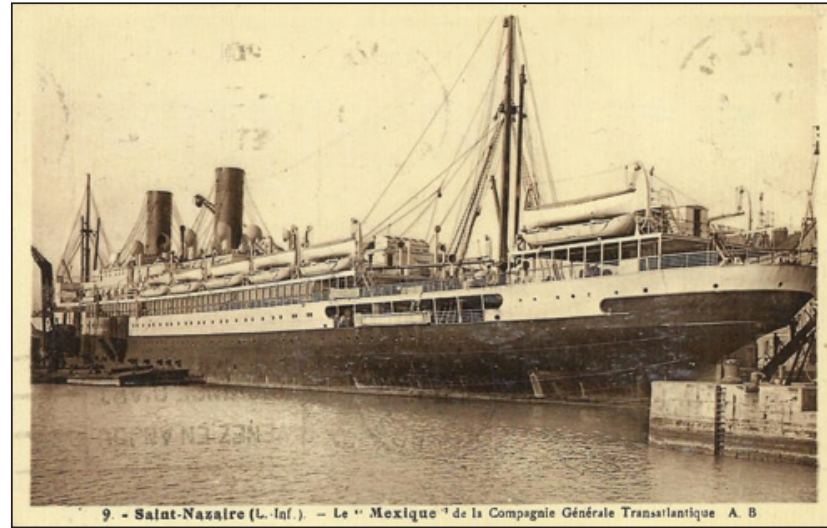

Buque Mexique laciones, pasaron temporadas en España artistas mexicanos (Diego Rivera), escritores (Alfonso Reyes) o historiadores (Silvio Zavala). Por parte española, $y$ entre otros, viajaron a México y colaboraron en diversos proyectos culturales de allá León Felipe, Rafael Altamira y Valle-Inclán.

Con el inicio de la Guerra Civil, la ayuda mexicana no solo fue militar, sino también humanitaria. En junio de 1937 partió de España rumbo a América el buque Mexique con unos 500 niños de ambos sexos, de entre cinco y doce años. Por invitación directa del presidente mexicano, los niños desembarcaron en Veracruz y fueron trasladados a Morelia, instalándose en la escuela España-México, creada especialmente para recibirlos y atenderlos hasta el fin de la guerra (serán los llamados «niños de Morelia»). La defensa de la legalidad republicana española del presidente Cárdenas en los foros internacionales y la hospitalidad del pueblo mexicano hicieron posible que México diera asilo a miles de refugiados españoles a los que ayudó y concedió la nacionalidad mexicana. De ese modo se entiende que cuando el gobierno republicano español, por medio del SERE (Servicio de Evacuación de Republicanos Españoles), preparó la salida de refugiados españoles en los campos de concentración franceses, contara con la ayuda de la embajada mexicana en Francia; así, recién finalizada la Guerra Civil, en mayo de 1939, zarpó desde el puerto de Sête con destino a México el Sinaia, enviado por el SERE, con ayuda del gobierno mexicano, llegando al puerto de Veracruz el 13 de junio de 1939. Le siguieron hasta la primavera de 1940 otros veintisiete barcos que llevaron a aquel país a casi seis mil españoles. Aunque no existen cifras exactas, se estima que, entre el fin de la Guerra Civil y 1945, llegaron a México de 12.000 a 20.000 refugiados (Ruiz-Funes 41).

El exilio español en México tuvo características sociológicas de especial importancia, ya que, aunque la formaron gentes de muy diferentes profesiones y distintas ideologías (desde la extrema izquierda a la derecha constitucional), hubo muchos profesionales liberales, artistas, universitarios y políticos, quienes, además de estar en los años más productivos de su existencia, representaban la parte más importante de la intelectualidad y la cultura de la España de la $2^{a}$ República; entre ellos, llegaron allá casi un tercio de los millares de maestros, pedagogos, profesores universitarios e inspectores de enseñanza que tuvieron que salir de España tras la guerra. De todos modos el exilio no fue tan mayoritariamente intelectual y cultural como, a menudo, se ha dicho, porque en la España de los años 30, con más de la mitad de la población analfabeta, ¿cuántos intelectuales podría haber? Lo que sí es cierto es que fue muy importante el impacto que supuso en la sociedad mexicana (sobre todo en las universidades) la llegada de un buen número de catedráticos, ingenieros, arquitectos o médicos. Desde el mismo momento de la llegada de los exiliados españoles de la posguerra, México los acogió con cordialidad; pese a ello, y aunque muchos jamás regresaron a España y se sintieron plenamente integrados en el país de acogida, no pudieron evitar los sentimientos de desarraigo y lejanía. Además, al drama que, en sí mismo, tuvieron que vivir los exiliados españoles (haber sido derrotados y tener que emprender el éxodo), se unió el frecuente sentimiento de culpabilidad que muchos de ellos experimentaron y del que sería un ejemplo el escritor Manuel Altolaguirre.

Llegaron a México profesores, arquitectos, artistas, ingenieros, médicos y muchísimos

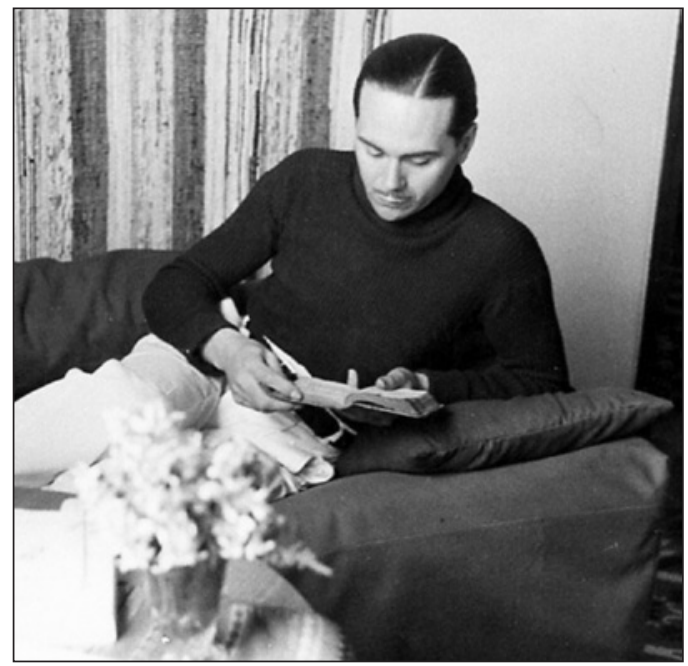

Luis Cernuda. 
escritores españoles: León Felipe, Moreno Villa, Juan Larrea, Pedro Garfias, Juan José Domenchina, Emilio Prados, Manuel Altolaguirre, Cernuda, Juan Rejano, Gil-Albert, Concha Méndez, Enrique Díez-Canedo, Antoniorrobles, Salvador Bartolozzi, José Carner, Magda Donato..., además de las frecuentes y largas visitas que hicieron otros que se asentaron en otros países, como Pedro Salinas o Jorge Guillén; escritores que pertenecían a diversas generaciones o promociones de la literatura española que, tras la guerra, quedó dramáticamente rota.

\section{El final de un ambicioso proyecto educativo}

Uno de los pilares del proyecto político educativo de la $2^{a}$ República fue la erradicación de la alta tasa de analfabetismo que tenía España (superior al 32\%), para lo que se pensó que era necesario hacer profundas reformas del sistema educativo, con el objetivo no solo de disponer de escuelas bien dotadas de medios y de maestros bien formados que garantizaran la educación de todos los niños españoles en edad escolar, sino también de cambiar los estudios de bachillerato, potenciar los centros universitarios y crear ambiciosos programas de cultura popular. En aquel proyecto la lectura fue objetivo primordial, lo que posibilitó la existencia de una verdadera promoción editorial, en la que el libro infantil empezó a tener importancia en España.

Pero aquel proyecto de educación popular que propició la aprobación del Plan Profesional del Magisterio, la creación de las Misiones Pedagógicas ${ }^{1}$, la difusión de programas de educación no formal, o la implantación de la escuela para adultos, no tuvo tiempo ni estabilidad para reorganizar todo el sistema educativo, desde la escuela a la universidad. La Guerra Civil y el triunfo de los sublevados provocaron que partieran al exilio numerosos maestros, profesores de enseñanzas medias, inspectores de enseñanza y pedagogos republicanos españoles, comprometidos con la renovación educativa auspiciada por la $2^{\mathrm{a}}$ República.

Aquella política educativa, en la que se unían ideas de diversa procedencia: del movimiento ilustrado del siglo xviII, del socialismo español y, sobre todo, de la Institución Libre de Enseñanza, fue rechazada de plano por todos los estamentos sociales y partidos políticos contrarios a la República. Los que, desde postulados fascistas, se alzaron contra ella, sabían bien que un pueblo educado es más crítico y, por tanto, más peligroso para quienes reprimen las libertades; por ello, sin duda, tras la Guerra Civil los nuevos gobernantes procuraron destruir todo lo hecho hasta entonces, persiguiendo y reprimiendo, con especial ensañamiento, a miles de profesionales de la educación que habían hecho posible aquel «milagro educativo», siendo muchos también los que lograron exiliarse. Algunos estudios hablan de una depuración (asesinados, encarcelados y exiliados) superior al 20\% del total del censo de funcionarios del Ministerio de Instrucción Pública (Hernández Díaz, en línea), que afectó a profesores, maestros, catedráticos, inspectores y administradores de la educación, no solo a los que tuvieron responsabilidades en aquel modelo educativo, sino también a quienes, simplemente, mostraron simpatía por el mismo.

Uno de los proyectos educativos más interesantes del Ministerio de Instrucción Pública de la $2^{a}$ República fue la creación de bibliotecas escolares; el decreto de 7 de agosto de 1931, que establecía la obligatoriedad para todas las escuelas primarias de contar con una biblioteca abierta, libre y gratuita para niños y para adultos, fue determinante para que se hubieran creado más de 5.000 bibliotecas a principios de 1935, dejando a los maestros la responsabilidad de su funcionamiento, y al Patronato de las Misiones Pedagógicas y a la dirección del Museo Pedagógico Nacional la selección de los fondos bibliográficos con que se dotaban las mismas.

Las memorias anuales del Patronato de Misiones Pedagógicas daban cuenta de la atención prestada a la confección de los lotes destinados a la formación de aquellas bibliotecas, cuidando la adecuada proporción de títulos de obras literarias, junto a los de las restantes ramas del saber y a otras lecturas infantiles y juveniles. Asimismo, daban cuenta de los criterios de selección para integrar en aquellos lotes los clásicos infantiles, las adaptaciones de clásicos, las aventuras, las lecturas geográficas y las biografías. En tal labor destacaba la clara convicción de sus responsables acerca de la promoción cultural derivada del fomento de la lectura infantil y juvenil, basada además en la idea de que los propios muchachos moverían a leer a sus padres (García Padrino, «Primeros clásicos» 57-58). En el Decreto de creación de las Misiones Pedagógicas (29/05/1931) se puede leer el propósito que las guiaba: «Hay en este propósito, además del beneficio que la enseñanza nacional puede recibir, el deber en que se halla el nuevo régimen [la $2^{a}$ República] de levantar el nivel cultural y ciudadano (...) y ayudar a la incorporación de Es paña al conjunto de los pueblos más adelantados». Diferentes programas de las Misiones llevaron a los pueblos más aislados y atrasados de España cine, teatro, pintura y libros, con participación directa de escritores, artistas e intelectuales comprometidos con el proyecto.
Literatura infantil y educación en el exilio español en México

PEDRO C. CERRILLO 
El Patronato de las Misiones Pedagógicas, nombrado para diseñar las que debían seguirse siempre estuvo presidido por Manuel Bartolomé Cossío, y de él formaron parte, entre otros y en diversos momentos, Luis Álvarez Santullano, Ángel Llorca, Pedro Salinas, Jorge Guillén, Gerardo Diego o Antonio Machado. La mayor parte de los que trabajaron como «misioneros» fueron maestros, inspectores de enseñanza, profesores de bachillerato o estudiantes universitarios. Entre 1931 y 1933 se crearon tres mil ciento cincuenta y una bibliotecas, mediante el envío de otros tantos lotes iniciales integrados por cien volúmenes preparados ya para su uso y préstamo a los lectores. Después se cuidaba su incremento con nuevas obras y se orientaba su funcionamiento, según disponía una orden ministerial (25 de abril de 1932), recurriendo a los Inspectores de Enseñanza Primaria para que velasen por el rendimiento de las bibliotecas y les brindasen todo el apoyo posible.

Las compras masivas de libros realizadas por las Misiones Pedagógicas impulsaron el mercado editorial, particularmente el de los libros infantiles y juveniles. Más de la mitad del presupuesto total de las Misiones se destinó a la dotación de las llamadas bibliotecas circulantes, que llegaron a cientos de pueblos y aldeas que no tenían, en muchas ocasiones, ni agua ni luz. Una de las selecciones de libros que más se repartió por las escuelas de las poblaciones rurales fue la denominada «Biblioteca Z», compuesta por 100 libros, entre los que se incluían títulos clásicos (el Quijote, Fausto, Conde Lucanor, el Buscón), pero también adaptaciones de $\mathrm{M}^{\mathrm{a}}$ Luz Morales para la colección Araluce (La Odisea o La Ilíada), obras de autores españoles contemporáneos (Unamuno, Antonio Machado, Pío Baroja, Juan Ramón Jiménez o Alejandro Casona), novelas juveniles ( La cabaña del tío Tom, de Beecher; La isla del tesoro, de Stevenson; o Los hijos del capitán Grant, de Verne), clásicos infantiles universales (Cuentos de los hermanos Grimm y de Perrault; Alicia en el País de las maravillas, de Carroll; o Peter Pan $y$ Wendy, de Barrie), y ediciones infantiles españolas recientes (Pinocho del italiano Collodi o Cuentos de Calleja).

El firme propósito de Bartolomé Cossío fue que las Misiones Pedagógicas no solo crearan bibliotecas circulantes, sino también que ofrecieran «obras escolares complementarias» $\mathrm{y}$ acciones culturales de diverso tipo que pudieran llegar a todos los rincones de España, por medio de maestros comprometidos con esa innovadora acción social que quería difundir conocimientos y animar cultural y espiritualmente a los ciudadanos, sobre todo a quienes vivían en localidades rurales. En ese contexto un proyecto muy interesante fue el llamado «Teatro y Coro del Pueblo», creado el 15 de mayo de 1932, con el dramaturgo Alejandro Casona y el músico Eduardo Martínez Torner como responsables, que llevó por más de quinientos pueblos españoles, la mayoría de los cuales nunca habían visto una obra de teatro, en actuaciones al aire libre casi siempre, farsas, leyendas y comedias, teatro de ecos tradicionales, salpicado de romances $\mathrm{y}$ canciones populares, que empatizaba muy bien con aquel público asombrado.

Otros proyectos culturales impulsados por los gobiernos republicanos, relacionados con el mundo del libro, fueron: la organización de Ferias del Libro en diversas ciudades españolas, la primera de las cuales tuvo lugar en Madrid, en abril de 1933, dedicándose una jornada, la del 27 de abril, a los libros infantiles y juveniles; la celebración de Semanas del Libro Infantil; y la realización de la I Exposición del Libro Infantil que, organizada por la Cámara Oficial del Libro, tuvo lugar en el Círculo de Bellas Artes de Madrid en diciembre de 1935 .

En 1932 se hizo una convocatoria para libros escolares en el Concurso Nacional de Literatura. El jurado, formado por María Goyri, esposa de Menéndez Pidal, María Zambrano y Fernando Sainz, concedió el primer premio a Alejandro Casona por su libro infantil Flor de leyendas, pero en el acta se incluyó el acuerdo unánime del jurado de reducir la dotación económica del premio para conceder una mención especial a Hermanos Monigotes de Antoniorrobles, que vería la luz tres años después en la editorial Juventud con el título Hermanos Monigotes (Visión alegre, amable $y$ simple de las cosas de la vida), con viñetas del propio autor e ilustraciones de J. Vinyals.

Hubo también en aquellos años un decidido interés de las autoridades educativas por iniciar a los niños en la lectura de poesía, por medio de la recuperación y fijación escrita de la gran tradición española de poesía popular, impulsando la edición de antologías y colecciones de gran interés, de las que son buenos ejemplos Canciones infantiles (1934), de María Rodrigo y Elena Fortún, que ofrecía una 
interesantísima selección de canciones populares de tradición infantil que estaban vivas en la colectividad y que se difundían oralmente. Y Poesía infantil recitable (1935), magnífica obra de dos miembros de las Misiones Pedagógicas, el inspector de enseñanza José Luis Sánchez Trincado y el maestro Rafael Olivares Figueroa: es una antología bien estructurada

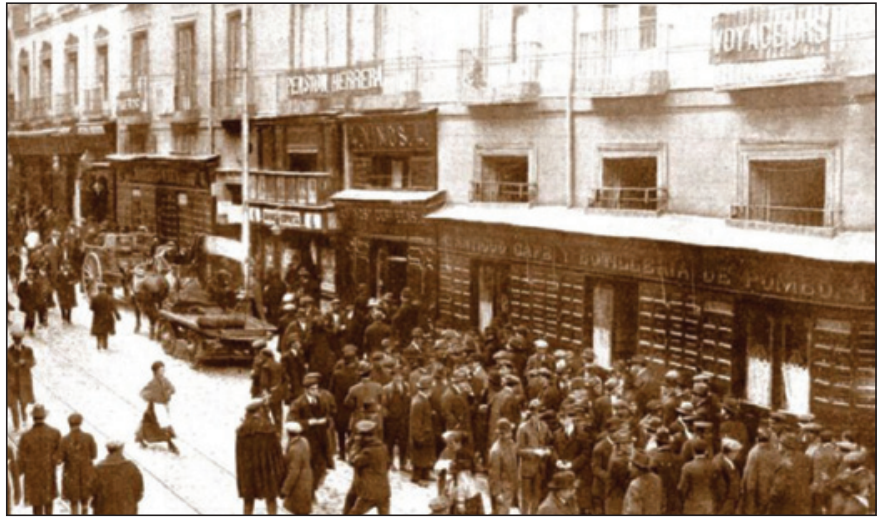

Café Pombo.

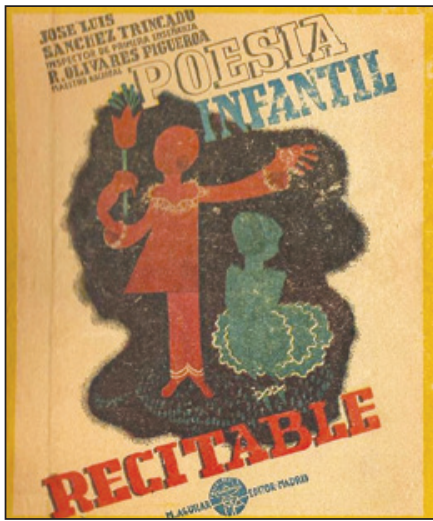

Poesía infantil recitable (1935). que ofrece poemas de autor muy bien seleccionados, desde Gil Vicente a Lorca o Alberti, pasando por Lope de Vega, Góngora, Tirso de Molina, Unamuno, Antonio Machado, Pedro Salinas o Jorge Guillén, entre otros, incluyendo también poesía popular (romances anónimos, adivinanzas o canciones escenificadas infantiles).

\section{El primer impulso de la LIJ en España}

Durante los años de la $2^{\text {a }}$ República, escritores consolidados como Juan Ramón Jiménez, Jardiel Poncela, José López Rubio, Valle Inclán, Benjamín Jarnés, Rafael Alberti o García Lorca no solo apoyaron y defendieron una literatura infantil nueva, sino que algunos de ellos escribieron para niños. Lo mismo sucedió con otros escritores que se acercaron, con más o menos intensidad, a la estética de las vanguardias, algunos de los cuales pertenecían al grupo que se hizo famoso en la tertulia del Café Pombo de Madrid: Manuel Abril, Gómez de la Serna, Antoniorrobles, $\mathrm{M}^{\mathrm{a}}$ Teresa León o Salvador Bartolozzi.

El apoyo del Estado resulta esencial, puesto que integra el libro infantil en sus políticas culturales y educativas. Durante la República se confirma el interés por la promoción de la lectura como uno de los ejes de la política cultural del Estado y, al margen de la política educativa y de bibliotecas, se proponen iniciativas que darán a la literatura infantil una mayor visibilidad: las ferias del libros, la exposición de libros infantiles en los escaparates de las librerías (...) (Llorens 7).

La LIJ española vivió en aquellos años una renovación importante, en temas, en formas y en estética. A los autores mencionados habría que añadir Magda Donato, Josefina Bolinaga,

Elena Fortún o M ${ }^{a}$ Luz Morales. Además, en las ediciones de libros infantiles solían colaborar artistas y dibujantes como Lola Anglada, Rafael Barradas, Ramón Gaya, Moreno Villa, K-Hito o Ramón Pujol.

\begin{abstract}
Al final de los años 1920 y a lo largo de los años 1930 se ha confirmado el interés hacia el género [se refiere a la LIJ] con autores más numerosos y una práctica diversa, que tres autores, comprometidos con la política cultural de la República, expresan de modo ejemplar. Se trata de Bartolozzi, Antoniorrobles y Elena Fortún, cuyos aportes respectivos abarcan aspectos tan diversos como la modernización de la ilustración, la exploración de lo absurdo e imaginario, o la mezcla de crítica social y de análisis psicológico. Los tres se comprometerán con la acción cultural y tendrán que dejar España en 1939 (Franco 261).
\end{abstract}

Los textos literarios que se escribieron en aquellos años expresamente para niños, o las recopilaciones que se llevaron a cabo para uso escolar, empezaron a dar importancia a la imaginación y a la fantasía, rechazando los valores meramente doctrinales, morales o didácticos, demostrando interés por la tradición popular española, en el doble sentido de reconocerla y salvaguardarla, así como por dar a conocer historias y leyendas de ámbito universal, o grandes obras de la literatura clásica (divulgadas en adaptaciones muy dignas por la editorial Araluce).

Durante aquellos años de la República existieron en España una serie de editoriales que, con mayor o menor intensidad, decidieron publicar LIJ: Araluce, Sopena, Salvat, Bastinos, Ciap, Espasa-Calpe, Rivadeneyra, Aguilar, Molino, Juventud o Calleja. La aparición de la editorial Bastinos en Barcelona (en 1852), como editora de libros infantiles,
Literatura infantil y educación en el exilio español en México

PEDRO C. CERRILLO 


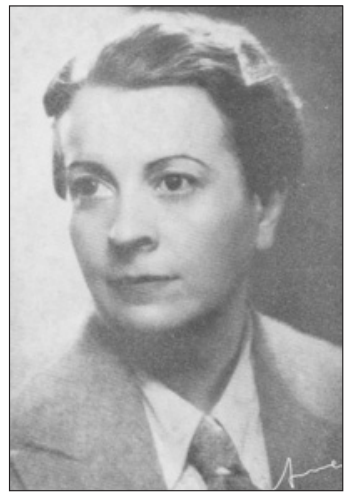

Elena Fortún. y la publicación de los primeros cuentos para niños de la editorial Calleja, en Madrid en 1884, marcaron, probablemente, el inicio de una LIJ española diferente, en la que se ofrecía un modelo distinto de libros infantiles, apartado de sus anteriores corsés educativos. Precisamente Bastinos y Calleja simbolizan, de algún modo, la modernización del mundo de la edición de libros para niños en España, preocupándose tanto por el valor literario de los textos como por las ilustraciones y el diseño de las colecciones. (García Padrino, Libros y literatura 17-38).

La Guerra Civil conllevó una completa ruptura con todo lo que hasta entonces, en todos los ámbitos de la vida, se estaba haciendo (Cerrillo y Miaja 44-50). Además, se produjo un enconado choque entre dos maneras muy diferentes de entender la literatura para niños y la función que la misma debía cumplir en el contexto educativo. Si durante los años que duró la guerra, la LIJ que se hizo en España estuvo muy marcada por los intereses ideológicos, a veces incluso políticos, de los dos bandos (Sánchez Ortiz y Cerrillo 85-99), una vez finalizada la contienda, los vencedores denigraron casi todo lo que hasta entonces se había escrito y editado, imponiendo normas y reglas que impedían que la LIJ pudiera ser enjuiciada solo por sus méritos literarios o artísticos, ya que era obligatorio evitar ciertos temas o transmitir determinados valores.

Al acabar la Guerra Civil se inició el largo periodo autocrático ya conocido, en el que se vinieron abajo los logros alcanzados por la LIJ española en los años anteriores. Muchos de los autores que los habían protagonizado (Bartolozzi, Antoniorrobles, Casona, Martínez Torner, Manuel Abril, Moreno Villa, Magda Donato, $\mathrm{M}^{a}$ Teresa León, Elena Fortún), también bastantes ilustradores (Bardasano, Peinador, Avel.lí Artís Gener, Alma Tapia, Ramón Gaya, Darío Carmona), se marcharon al exilio, iniciando nuevos caminos, en algunos casos muy diferentes entre sí, pues, además del desarraigo que les supuso el éxodo, tuvieron que buscar maneras nuevas de comunicarse, cuando no de ganarse la vida.

Muchos de los autores exiliados habían participado en el gran movimiento de innovación artística y educativa que recorre los años veinte y treinta en España. Bien por sus obras de claro lenguaje vanguardista, tanto en la literatura como en la ilustración, bien por la búsqueda de nuevas formas dramáticas o por la defensa de nuevos cauces para la educación popular (...) habían contribuido a crear un nuevo concepto del arte y la literatura que los niños podían disfrutar, al margen de que se hubieran creado para ellos. Es evidente que el contexto que explica y justifica el poderoso impulso innovador de las vanguardias desaparece, y solo en algunos casos es posible una cierta continuidad temática y estética de estos planteamientos (Sotomayor 122).

\section{La obra de los exiliados republicanos espa- ñoles en México}

México fue el país que acogió a más exiliados republicanos profesionales de la enseñanza, más de la cuarta parte del total. Muchos ellos se incorporaron a universidades mexicanas, impulsaron centros de investigación, crearon en el país de acogida editoriales y centros educativos para la enseñanza primaria, escribieron libros (también para niños y jóvenes), o asesoraron al Ministerio de Educación mexicano que no quiso desaprovechar su experiencia en el modelo educativo innovador en el que habían trabajado en España.

En México se exiliaron tres promociones de españoles de diferentes edades: los que vivieron la guerra en edad adulta, quienes la vivieron como adolescentes $\mathrm{y}$, finalmente, los que durante la misma eran muy niños $o$, incluso, como hijos de exiliados, nacieron en el país de acogida. Los más veteranos eran, en su gran mayoría, profesionales cuyo trabajo - en algunos casos - ya era conocido y valorado en México antes de su llegada, lo que facilitó que pudieran ejercer los mismos trabajos que desempeñaban en España, con la excepción de algunos de los que tenían una edad demasiado avanzada, a quienes la nueva situación les supuso una barrera casi siempre infranqueable para adaptarse a la vida y a las costumbres de México.

El impulso de la cultura española en los años anteriores al inicio de la Guerra Civil, en el que tuvieron mucho protagonismo la mayoría de los exiliados a México, no se detuvo en aquel país. Muy pronto, los refugiados crearon centros culturales, instituciones, escuelas o editoriales que hicieran posible la organización y coordinación de actividades que surgían de la iniciativa de todos ellos. 


\section{a) Instituciones}

\section{El Ateneo Español de México}

El Ateneo Español de México representó $\mathrm{y}$, de algún modo, aún hoy representa un papel importantísimo en el ámbito intelectual y cultural español, representando la historia viva del exilio republicano en aquel país. Sirva como ejemplo de ello, y en relación con la LIJ, que el 5 de septiembre de 1995, en el marco del ciclo que el Ateneo programó sobre «Los exiliados españoles en el teatro, el cine y la televisión de México», tuvo lugar un homenaje a Magda Donato y Salvador Bartolozzi, en el que participaron Magda Carreño, las hermanas Azucena y Gloria Rodríguez y Aurora Miramontes, al tiempo que se exhibieron pinturas y dibujos de Bartolozzi.

\section{La Casa de España / El Colegio de México}

Tras la llegada de los primeros intelectuales españoles a México, en agosto de 1938 se fundó La Casa de España, desde donde se impartieron clases a varias instituciones académicas mexicanas, al tiempo que fue un importante centro de investigación, en el que encontraron acomodo algunos de aquellos intelectuales españoles: Díez-Canedo, José Gaos, Moreno Villa, León Felipe, Joaquín Xirau o María Zambrano. La Casa de España fue el embrión de lo que, en el mes de octubre de 1940, pasó a ser El Colegio de México, primero dirigido por Alfonso Reyes y, luego, por Daniel Cosío, que hoy es una de las instituciones culturales y educativas más importante del mundo, con destacados centros de investigación. Con la principal responsabilidad de formar a profesores universitarios y facilitar la investigación en los ámbitos de las ciencias sociales y las humanidades, El Colegio de México no ha dejado de funcionar desde el día de su nacimiento, siendo una institución de referencia en todo el mundo hispánico, muy valorada por científicos de diversas áreas del saber.

\section{b) Centros educativos}

Tras la llegada de los exiliados españoles se crearon bastantes escuelas e institutos con el fin de atender las necesidades educativas de sus hijos, con la responsabilidad académica de los maestros republicanos exiliados: Ins- tituto Luis Vives, Colegio Madrid, Instituto hispano-mexicano Ruiz de Alarcón, Patronato Cervantes, Escuela Manuel Bartolomé Cossio; pocos chicos españoles se integraron en colegios mexicanos, quizá porque los exiliados siempre pensaron, al menos durante los primeros quince años, que su exilio era temporal y que, pronto, podrían regresar a España.

Muchos de aquellos maestros exiliados se habían formado en los postulados del Krausismo y la Institución Libre de Enseñanza, que reivindicaban una filosofía práctica para el cambio social, la educación y la ética, así como una pedagogía basada en la comprensión más que en la enseñanza memorística, obligando a poner en contacto directo al alumno con la naturaleza y con cualquier objeto de conocimiento, destacando la importancia de las clases experimentales, las excursiones y la literatura popular entendida como expresión del espíritu nacional o «Volkgeist». Entre los principios de esta escuela educadora y creativa destacó el interés por las posibilidades didácticas de la literatura tradicional: en su declaración de principios, publicados sucesivamente en el Boletín de la Institución (BILE) desde su aparición en 1877 hasta el final de su primera época en marzo de 1936, se recogía el principio de la pedagogía activa y en íntimo contacto con la vida - el método intuitivo, expresión acuñada por Pestalozzi y Fröebel-, destacando la importancia de enseñar a través de lo activo, nunca con puras teorías, sino mediante experiencias personales, otorgando especial importancia a la formación del sentido estético, por lo que la música, el arte popular, las canciones y juegos, el teatro, etc., fueron cultivados con especial atención.

Los institucionistas eliminaron de las aulas el libro de texto como instrumento principal de la enseñanza en clase, por lo que la selección de lecturas realizadas por los maestros cobró especial relevancia en las clases de lengua y literatura, valiéndose para ello de recopilaciones folclóricas realizadas en el aula, antologías de cuentos y leyendas, fragmentos de textos literarios de autores consagrados, o relatos y poemas escritos por ellos mismos. De todo ello encontramos diversos ejemplos entre los exiliados, pues en su docencia en tierras mexicanas pusieron en práctica buena parte de estos ideales aprendidos durante su formación en España. Es difícil en algunos casos hablar de maestros escritores de LIJ, pues en muchas ocasiones sus creaciones lite-
Literatura infantil y educación en el exilio español en México

PEDRO C. CERRILLO 
2

Para un conocimiento más ex haustivo de su vida, puede consultarse Jiménez Mier y Terán (1999)

Literatura infantil y educación en el exilio español en México

PEDRO C. CERRILLO rarias quedaron escondidas en las páginas de los cuadernos de trabajo de sus alumnos, en libros de texto o en los cuadernillos creados en las aulas de las «escuelas Freinet», aunque hubo maestros que sí publicaron algunos de sus cuentos y relatos, como, por ejemplo, $\mathrm{M}^{\mathrm{a}}$ Mercedes Aguilar Ventura, «la Miss». Sin embargo, sí es importante su labor en la difusión de la literatura para niños, tanto por la utilización de textos de buena calidad literaria para sus clases, como por su selección para manuales y libros de lectura que muchos de ellos editaban, y por el fomento de la creatividad literaria en los trabajos de clase con sus alumnos.

El ideario pedagógico de Freinet había llegado a España en el primer tercio del siglo $\mathrm{xx}$ gracias al interés, principalmente, de Herminio Almendros, Patricio Redondo y José de Tapia: «los tres introducen en España esta técnica Freinet, avanzados los años veinte, de tan hondo calado escolar como más tarde se ha visto y comprobado en la pedagogía y en la práctica escolar de todo el mundo» (Hernández Díaz, en línea). Las técnicas Freinet - diarios, textos y dibujos libres, asambleas, investigación en el medio, excursiones, bibliotecas de clase, método natural de lectura y escritura - fueron parte de aquella innovación pedagógica de principios del siglo $\mathrm{xx}$ cuyo objetivo principal en España fue introducir un nuevo modelo de organización escolar y dinamizar la actividad didáctica de las aulas, rompiendo así el modelo de enseñanza tradicional con una alternativa educativa más avanzada desde el punto de vista pedagógico. En poco más de diez años, las escuelas españolas «Freinet» alcanzaron amplia repercusión internacional, pues el grupo pionero y responsable de su implantación, encabezado por los tres maestros mencionados, tuvo una fuerte vinculación con el propio Célestin Freinet y otros colectivos de maestros en distintos países europeos que también aplicaban esas prácticas.

Dos de los impulsores de las «escuelas Freinet» en España, José de Tapia Bujalance y Patricio Redondo Moreno, son también, junto a Ramón Costa Jou, los pioneros en la práctica de la educación Freinet en México, y fundadores de sendas escuelas activas. José de Tapia (1896-1989)2 - conocido popularmente en México como «el maestro Pepe»-, responsable en España de los movimientos cooperativos en la educación y fundador con el Grupo Batec (del que fue miembro) de la Cooperativa Española Freinet, llegó a México con una amplia experiencia educativa, y no paró de ejercitar su actividad docente hasta el final de su vida, a los 75 años. Patricio Redondo comenzó a dar clase a niños de la calle, creando debajo de un árbol un colegio que no dejaría de crecer hasta los años cincuenta, y en el que puso en práctica la metodología didáctica basada en las técnicas freinetistas, dando a su escuela de San Andrés de Tuxtla el nombre de Escuela Experimental Freinet.

Esa firme convicción en la bondad de las técnicas Freinet tuvo su expresión en la escuela de San Andrés de Tuxtla. Desde sus inicios el eje principal de la organización didáctica fueron las técnicas del «texto libre» y «la imprenta escolar». Los alumnos redactaban un texto, lo componían con letras de molde y lo imprimían con pequeñas prensas escolares. Una vez impresos los textos, se compaginaban revistas escolares que llevaban títulos tan sugerentes como Xóchitl, Nacú, Mi afán, Mexicanitos, en los que se incluían bellas ilustraciones dibujadas por los mismos alumnos de la escuela (Cruz Orozco 50).

Esos cuadernos, como otros muchos realizados en las aulas de tantos colegios en los que se llevaron a cabo estas actividades - como la Escuela Manuel Bartolomé Cossío, por poner un ejemplo-, contienen parte de la literatura infantil del momento: poemas y cuentos clásicos que el maestro proponía como ejercicio de lectura o recitación, y que los escolares ilustraban; reinterpretaciones y reescritura de conocidas composiciones populares o de autores latinoamericanos que los alumnos llevaban a la imprenta; o textos en verso o prosa, que realizados e ilustrados por los propios niños dentro del aula, son parte de esta literatura hecha por y para los niños, retazos literarios que se encuentran en el interior de estos magníficos trabajos escolares artesanos, no destinados a su publicación y, por tanto, de difícil localización fuera de los hogares de los propios alumnos, las bibliotecas de los colegios en que se realizaron o los archivos de instituciones preocupadas por su conservación, como El Colegio de México o el Ateneo Español.

\section{c) Editoriales}

El firme deseo de muchos exiliados españoles en México de continuar los trabajos 
a los que se habían dedicado en España en años anteriores les llevó a crear empresas relacionadas con el mundo del libro y la lectura: editoriales, imprentas, librerías o publicaciones periódicas. En México los españoles pudieron expresarse con total libertad, a diferencia de los compatriotas que se quedaron en España, en donde la censura era un fortísimo mecanismo de represión y prohibición para quienes escribían, editaban, ilustraban o vendían libros, revistas o periódicos. Entre otras, se fundaron las editoriales Costa-Amic, Proa, Arcos, Xóchitl, Centauro, Ediciones Educación, Leyenda, Séneca, Rex, Atlántida, España, Minerva, Ediapsa, Magister, Cima, Orión, Quetzal, España Nueva, algunas de las cuales publicaron libros infantiles y juveniles: Cartas a Platero (Paulita Brook, Proa, 194?), La duquesita y el dragón (Magda Donato, con ilustraciones de Salvador Bartolozzi, Leyenda, 1944), Mexicayotl (Ramón J. Sender, con viñetas de Darío Carmona, Quetzal, 1940), o Un poeta con dos ruedas. Cuentos para los 11 años de edad y sus alrededores (Antoniorrobles, con ilustraciones del propio autor, Costa-Amic, 1971).

Un caso especial es el de Ediapsa (Edición y Distribución Iberoamericana de Publicaciones, S.A.), creada el 7 de julio de 1939 en Ciudad de México por el periodista, diplomático y literato mexicano Martín Luis Guzmán y el exiliado español Rafael Giménez Siles, quien fue su director durante casi 40 años. La empresa inició sus trabajos editando y distribuyendo publicaciones en toda Hispanomérica, e inaugurando, en aquel mismo año, su primera librería en Ciudad de México: la Librería Juárez.

Giménez Siles, que llegó a México en junio de 1939 vía Nueva York, tenía un nutrido y notorio currículum como librero, impresor, editor y promotor cultural en España: organizador de la primera Feria Nacional del Libro en 1933; promotor de la adquisición y funcionamiento de «camiones librería» que, durante la $2^{\text {a }}$ República, llevaron libros a muchos pueblos españoles que no disponían de otra manera de acercarse a la lectura; fundador en 1928, junto con Juan Andrade y Graco Marsá, de la editorial Cenit, en la que se publicó una colección de LIJ, «Cuentos Cenit para niños», compuesta en su totalidad por traducciones del alemán y del ruso; y propietario de la editorial Estrella, creada en Valencia en 1937, especializada en publicaciones infantiles y juveniles, que tuvo continuidad en el exilio mexicano.

Ediapsa fue un grupo editorial con vocación de referente y difusor cultural para toda Latinoamérica, que puso en venta varias colecciones entre las que se encontraban: «Libros de buen Humor», dirigida por Benjamín Jarnés, y «Ediciones Musicales», cuyo primer libro Cantos para niños fue declarado libro de texto en las Escuelas Primarias y Secundarias de México (Caudet, Romance 30). En el ámbito escolar destaca la importante colección «Ediciones Pedagógicas y Escolares», que dirigían los exiliados Juan Comas y Antonio Ballesteros, este último maestro y pedagogo. La autoría de la mayor parte de los textos se debía a profesionales españoles exiliados: Martínez Torner, La literatura en la escuela primaria (1940); Antonio Ballesteros, Cómo se organiza la cooperación en la escuela primaria (1940); Juan Comas, Cómo se comprueba el trabajo escolar (1940); Regina Lago, Cómo se mide la inteligencia infantil (1940); Enrique Rioja, Las ciencias naturales en la escuela primaria (1940); Modesto Bargalló, La física en la escuela primaria (1940); o Emilia Elías de Ballesteros, La concentración de la enseñanza en la escuela primaria (1940).

Ediapsa editó la revista Rompetacones. Revista infantil de los jueves, que dirigía Antoniorrobles. La publicación debió tener muy corta vida, aunque sabemos que existieron al menos dos números (correspondientes a las fechas del 8 y el 15 de febrero de 1940), cuyas portadas (en ambos casos con los personajes de Botón, Don Nubarrón y Trimotor) aparecen reproducidas en Aurrecoechea y Bartra (115 y 416). Se trataba de una publicación infantil de ocho páginas en tamaño tabloide que contenía historietas, cuentos originales, acertijos, chistes, propuestas lúdicas de carácter didáctico, al precio de 15 centavos de peso el ejemplar.

Además de la edición propia, Ediapsa era distribuidora de las editoriales que Giménez Siles mantuvo como continuación de su labor en España: Nuestro Pueblo y la citada Estrella, «editorial para la juventud», ambas vinculadas al Partido Comunista. Estrella publicó las Aleluyas de Rompetacones, de Antoniorrobles (1939) en 20 volúmenes, con amplia publicidad ilustrada en la revista Romance. El otro libro publicado en México
Literatura infantil y educación en el exilio español en México

PEDRO C. CERRILLO 
por Estrella del que tenemos noticia, también anunciado en Romance, es: Las montañas y los hombres, de M. Ilin (1939), subtitulado «ocho relatos sobre la transformación de la naturaleza», dirigido al público juvenil, y que ya había sido editado por el mismo sello en Madrid en 1937.

\section{d) Publicaciones periódicas}

En el país de acogida, los exiliados republicanos españoles crearon o impulsaron diarios, semanarios y otras publicaciones de diversa periodicidad, entre otras: El Pasajero (fundada por José Bergamín en 1943), España peregrina (revista literaria creada en 1940 que, años después, se transformó en Cuadernos Americanos), España popular (semanario de orientación comunista), Las Españas (revista literaria que se editó entre 1946 y 1963), $\mathrm{Li}$ toral (revista literaria del mismo nombre que la fundada en Málaga, en 1927, por Emilio Prados y Manuel Altolaguirre, que en México fue editada por Moreno Villa, los propios Prados y Altolaguirre, Juan Rejano y Francisco Giner de los Ríos), Los cuatro gatos (revista de tono humorístico dirigida por Antoniorrobles, editada entre 1948 y 1951), o Romance. Revista popular hispanoamericana (editada por Ediapsa).

Respecto a las publicaciones periódicas infantiles, tenemos constancia de que en los barcos que llevaban refugiados españoles a México (Sinaia, Ipanema o Mexique) se escribieron periódicos a ciclostil, con secciones expresamente dirigidas a los niños. Por ejemplo, en el Sinaia: «En una tira de tres dibujos, con un pareado debajo de cada uno, se contaba la historia de un niño que no paraba de hacer travesuras en el barco y que, finalmente, se cayó al mar. He aquí los tres pareados: Este era un niño muy malo / que se llamaba Gonzalo. I A todas partes subia / sin saber por qué lo hacía. / Hasta que un día cayó, / y el pobrecito se abogó (Caudet, El exilio republicano en México 42).

Pero los exiliados españoles solo crearon una revista expresamente infantil: Alerta, efímera publicación de la JSU de España en México, de la que se editó un número mecanografiado en 1952 dedicado «A los niños españoles en México» (Caudet, El exilio republicano de 1939 321). Sí aparecieron colaboraciones de exiliados españoles que escribían o ilustraban libros infantiles o ju- veniles, más o menos intensas y continuadas, en algunas revistas infantiles mexicanas:

- Mañana. La revista de México, publicada en México D.F. desde septiembre de 1943. Revista semanal de información general, noticias y sociedad, que incluía semanalmente la sección «Para los niños», a cargo de Salvador Bartolozzi y Magda Donato, ocupando dos páginas normalmente; en ellas, Bartolozzi y Donato incluían adaptaciones propias de cuentos populares infantiles y tiras de historietas con aventuras de sus personajes Pipo y Pipa. La última vez que aparece la sección es en el no 210 (6 septiembre 1947), sin haberse realizado ningún comentario ni aviso de su desaparición.

- El amigo de los niños. Periódico infantil. Publicado en México D.F. (Imprenta Ortiz Rubio) a partir del 29 de marzo de 1965, bajo la dirección de Consuelo Pacheco Pantoja. En el no 18, de septiembre de 1966, en la página 6 se incluye un fragmento de Platero y yo, sin firmar ni decir el autor. En el n 24 , de diciembre de 1967, (s/p), aparece una «Canción de corro» de Alejandro Casona: «Las niñas en guirnalda / y la luna redonda: / dos panderetas blancas. / Arroyo claro, / fuente serena: / las niñas en guirnalda / bajo la luna llena.» Además, se incluían adivinanzas infantiles en todos sus números.

- Chapulín: la revista del niño mexicano, editada por la Secretaría de Educación Pública a partir de 1943; en diversos de sus números aparecieron las Nuevas aleluyas de Rompetacones de Antoniorrobles, y diversas Aventuras de Pinocho de Salvador Bartolozzi. En el no 12 se publicaron dos cuentos, sin indicar el autor, pero muy parecidos en la escritura y en la ilustración a los de Antoniorrobles: Fifí y Lilí e Historia de Juan Chinaco, el conscripto más chamaco. En el no 14 apareció otro cuento, $E l$ hombre verdadero y el hombre mentiroso. Cuento español del siglo XVI, adaptado por J. López Marichal e ilustrado por Julio Prieto.

\section{La LIJ y los exiliados españoles en México}

La literatura infantil y juvenil que hicieron los exiliados españoles en México es un excelente reflejo de lo anteriormente expuesto: temas, personajes, situaciones y escenarios 
propios del país de acogida aparecen en las primeras obras de LIJ que los españoles exiliados publican nada más llegar, junto con otras obras que, de algún modo, van a ser una continuación de lo hecho antes en España, particularmente porque sus protagonistas van a ser personajes que ya habían triunfado en la LIJ española de antes de la Guerra Civil.

Especialmente interesante es la continuación del interés por la poesía popular que se había manifestado en la $2^{a}$ República. Mercedes Díaz Roig (hija de exiliados) y $\mathrm{M}^{\mathrm{a}}$ Teresa Miaja (hija y nieta de exiliados ya nacida en México), recopilaron en Naranja dulce, limón partido una antología de la lírica popular infantil mexicana (El Colegio de México, 1979), con ilustraciones de Iliana Fuentes, que se convirtió en un libro de gran éxito y que sigue reeditándose; esos poemas infantiles muestran gran concomitancia con los de la tradición española, indicio de que la implantación y el trasvase de la literatura oral infantil desde la Península a Nueva España fue continuado y encontró allí gran resonancia.

Otro ejemplo sería el de Moreno Villa, autor e ilustrador en 1945 de un libro inolvidable para los niños mexicanos, Lo que sabía mi loro. Una colección folclórica infantil, impreso por Altolaguirre en la editorial Isla. Moreno Villa había llegado a México en 1937, casándose en 1939 con Consuelo Nieto, viuda de su amigo mexicano Genaro Estrada. De esa relación nació en 1941 su hijo José. Parece ser que la paternidad tardía (tenía ya casi 54 años) provocó en el artista la necesidad de hacer $L o$ que sabia mi loro, en donde se dan la mano la vida recién estrenada de su hijo y el pasado que representan las canciones y retahílas que Moreno Villa incluye en el libro, procedentes, en gran parte, de la lírica popular de tradición infantil hispana, un punto en común - como otros tantos - con sus amigos poetas del 27 , como Alberti o Lorca. Los textos que forman esta «colección folclórica infantil»-como él la llamó-, tiene un claro carácter misceláneo, y aunque predominan las composiciones del cancionero popular, tiene una decidida vocación cultural, pues en ellos late una confianza infinita en el poder de la palabra poética. Antonio Alatorre (36) ha señalado que el libro de Moreno Villa era autobiográfico «porque en él metió don Pepe su infancia», o al menos esa parte de la infancia que va asociada con la risa y la sonrisa, con el ritmo, con el juego y «con el juego más emocionante y más alegre y alegrador de todos: el lenguaje». Aleluyas, canciones escenificadas de diverso tipo (corro, fila, comba), adivinanzas, refranes, fragmentos del Quijote o de Platero y yo, fábulas («El cuervo y el zorro», p. e.), juegos mímicos para los más pequeños («Este puso un huevo...»), trabalenguas, burlas o versos «famosos» (entre ellos los conocidos de Bécquer «Volverán las oscuras golondrinas...») forman esta obra de contenidos tan heterogéneos, pero a la que, magistralmente, Moreno Villa da unidad por medio de la personalísima ilustración que creó para la edición, así como del texto caligrafiado de su propia mano.

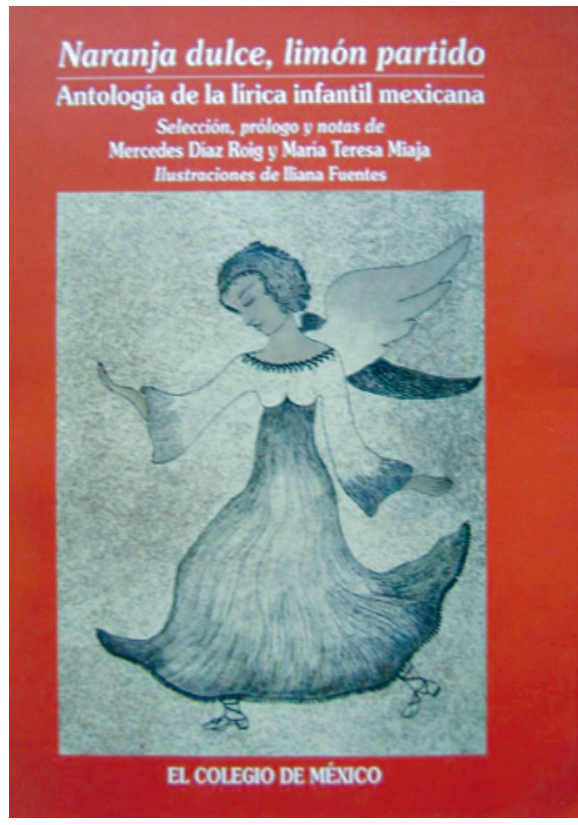

Naranja dulce, limón partido.
La participación de los exiliados en actividades relacionadas, directa o indirectamente, con la LIJ, en el país de acogida, fue en algunos casos muy intensa: especialmente relevantes son los casos de Antoniorrobles, Salvador Bartolozzi y Magda Donato (Cerrillo y Miaja 76-149), quienes no solo escribieron o ilustraron libros para chicos, sino que también participaron en programas de radio o televisión, hicieron teatro o rodaron películas, siempre con la base textual de algunas de sus obras literarias infantiles.

Hubo autores españoles exiliados en México, de reconocido prestigio y renombre, que se acercaron al público infantil en algún momento de su carrera. En la obra de Max Aub, que nunca escribió propiamente para niños, podemos encontrar algunas piezas que se relacionan con el mundo infantil: en Sala de Espera, 15, la revista que dirigía, aparecieron tres poemas de corte tradicional y con algún rasgo de canción infantil dedicados a sus hijas, textos que después pasarían a formar parte de Diario de Djelfa (fueron escritos durante el periodo de internamiento en un campo de concentración), aunque no en su edición original (México: Unión Distribuidora de Ediciones, 1944). Dos relatos suyos de corte mitológico-maravilloso están próximos a la narrativa infantil: aparecidos en 1955, el primero, La verdadera historia de los peces blancos de Pátzcuaro, cuenta la fabulosa historia del Emperador de China y los peces de su estanque, con el resultado de una gran
Literatura infantil y educación en el exilio español en México

PEDRO C. CERRILLO 


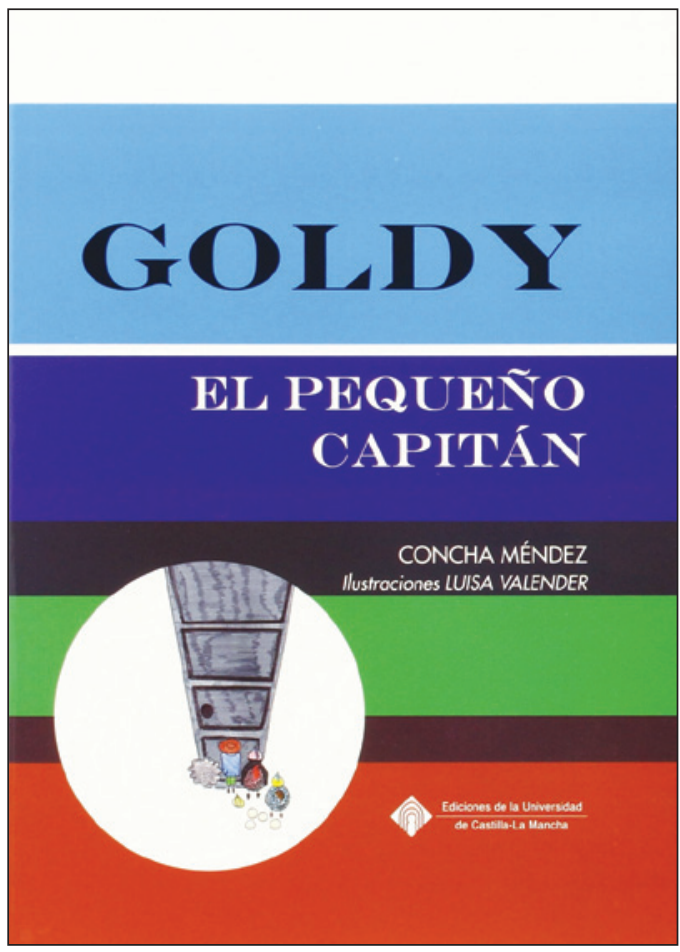

Goldy. El pequeño capitán.

migración que lleva a unos chinos a descubrir México; el segundo, Uba-Opa, narra la historia de un negro que atraviesa el océano hasta hacerse blanco, recibiendo las advertencias de varios peces, que le recuerdan los consejos dados y le añaden otros nuevos.

Josep Carner publicó Casos y pláticas de animales (Biblioteca Infantil Cervantes, 1944), con ilustraciones de Artís-Gener. Es un conjunto de cuentos con protagonistas de la fauna. Benjamín Jarnés (1943), quien solo permaneció en México hasta 1948, dirigió para el público infantil la enciclopedia El libro de oro de los niños. Un mundo maravilloso para la infancia; en sus páginas encontramos una canción de corro firmada por Alejandro Casona, de clara inspiración popular: «Las niñas en guirnalda / y la luna redonda: / dos panderetas blancas. / Arroyo claro, / fuente serena: / las niñas en guirnalda / bajo la luna llena» (1943, I, p. 71); también aparecen suertes: «Bajo la parra / nace la uva, / primero es verde, / después madura. / Tarará, tararí: / ¡El más valiente / fuera de aquí!» (1943, I, p. 36).

De Alejandro Casona se reeditó en México en 1961 (Fernández Editores) el libro infantil que le había merecido el Premio Nacional de Literatura en España en 1932: Flor de leyendas. Cuando apareció esta reedición Casona ya no residía en México, pero el hecho nos indica el interés por su literatura infantil en este país. Del teatro infantil de Casona, sabemos que al menos una pieza (Pinocho y Blancaflor. Farsa infantil en cinco estampas) fue escrita en México, aunque se estrenó en Buenos Aires el 16 de junio de 1940 por la compañía de Josefina Díaz y Catalina Bárcena, una nota autógrafa en el manuscrito reza: «Méjico. Arbeu. 14 de agosto de 1937» (Casona 9).

Concha Méndez publicó en México unas importantes reflexiones sobre el teatro infantil con el título "Teatro para niños», y es autora de un cuento infantil, inédito, Goldy. El pequeño capitán, fechado en 1958, que se conserva en copia mecanografiada con anotaciones manuscritas en la Residencia de Estudiantes de Madrid, y que publicó en 2012 Ediciones de la UCLM. Salvador de Madariaga publicó El sol, la luna y las estrellas. Romances a Beatriz (Hermes, 1954), con dibujos de Elisabeth von Rathlef; La dedicatoria indica que la destinataria es su nieta: «Hice estos romances para mi nieta Beatriz; y los publico por si otros abuelos se los quieren leer a sus nietos». Son imaginativos romances que tienen como protagonistas a astros que se comportan como seres humanos haciendo travesuras o disparates. Juan Marichal, uno de los intelectuales más activos del exilio, escribió también un libro para niños, El caballero del caracol (Biblioteca Chapulín, 1936), ilustrado por su hermano Carlos.

Otros autores menos conocidos también dedicaron obras a los niños; obras que constituyen una aportación nada desdeñable en el panorama que estamos dibujando. En muchos casos se trata de autores que compaginaron la literatura infantil con otras actividades, principalmente el periodismo y la traducción, o autores de los que se conoce una sola obra infantil, pero que colaboraron a mantener vivo el espíritu de una tradición bien asenta$\mathrm{da}$, como estamos viendo, de libros infantiles en el exilio: Tomás Segovia, Lorenzo Varela, Josep Roure-Torent o Anna Murià.

En el caso de los ilustradores de obras de LIJ exiliados en México hay que diferenciar entre dos generaciones: la de los artistas consolidados (Avel.lí Artís-Gener - Tisner-, José Bardasano, Salvador Bartolozzi, Darío Carmona, Ramón Gaya, Carlos Marichal, José Moreno Villa, Ramón Peinador, Miguel Prieto o Alma Tapia) y la de los transterrados 
más jóvenes, que terminaron su formación o hicieron toda su carrera como ilustradores en México (Elvira Gascón, Vicente Rojo o Moreno Capdevila), artistas universales que se adscriben en la estética contemporánea y continúan la herencia de sus antecesores españoles, a la que unen el influjo de la tradición mexicana.

\section{Final}

Con la llegada de la democracia y la subsiguiente recuperación de las libertades públicas y privadas, pareció como si todo lo anterior español, a veces incluso aquello que se remontaba a momentos y periodos que precedieron a la dictadura franquista, no existiera; parecía que se quisiera empezar de nuevo, a partir de un hipotético e injustificado punto cero. Ello ha conllevado, por desgracia, que exista en ámbitos culturales autodefinidos como modernos un olvido a veces demasiado fácil e irresponsable, de todos aquellos que defendieron la libertad mucho antes que los jóvenes y «modernos» demócratas. Se ha olvidado, entre todos los olvidados, a quienes lucharon desde sus obras o desde sus escritos para que la libertad no se perdiera, en unos momentos en que las amenazas eran más que evidentes; se ha olvidado, además, a quienes, una vez perdida aquella libertad de los primeros años treinta, tuvieron que marcharse de España porque no les era posible la convivencia con la Dictadura, entre ellos muchos artistas, escritores, editores, ilustradores, que trabajaron muy dignamente para la LIJ.

\section{Bibliografía citada}

Alatorre, Antonio. «De folklore infantil», $A r$ tes de México, XX: 162, 1973: 35-46.

Albornoz, Aurora de. «Poesía de la España peregrina: crónica incompleta». José L. Aranguren (coord.), El exilio español de 1939, Madrid: Taurus, IV, 1977: 11-108.

Aurrecoechea, Juan Manuel y Bartra, Armando. Puros cuentos II. Historia de la bistorieta en México. 1934-1950, México: Consejo Nacional para la Cultura y las Artes / Grijalbo, 1993.

Casona, Alejandro. Tres farsas infantiles, Gijón: Ediciones Noega, 1983.

Caudet, Francisco. Romance (1940-41): una revista del exilio, Madrid: Ediciones Porrúa Turanzas, 1975.

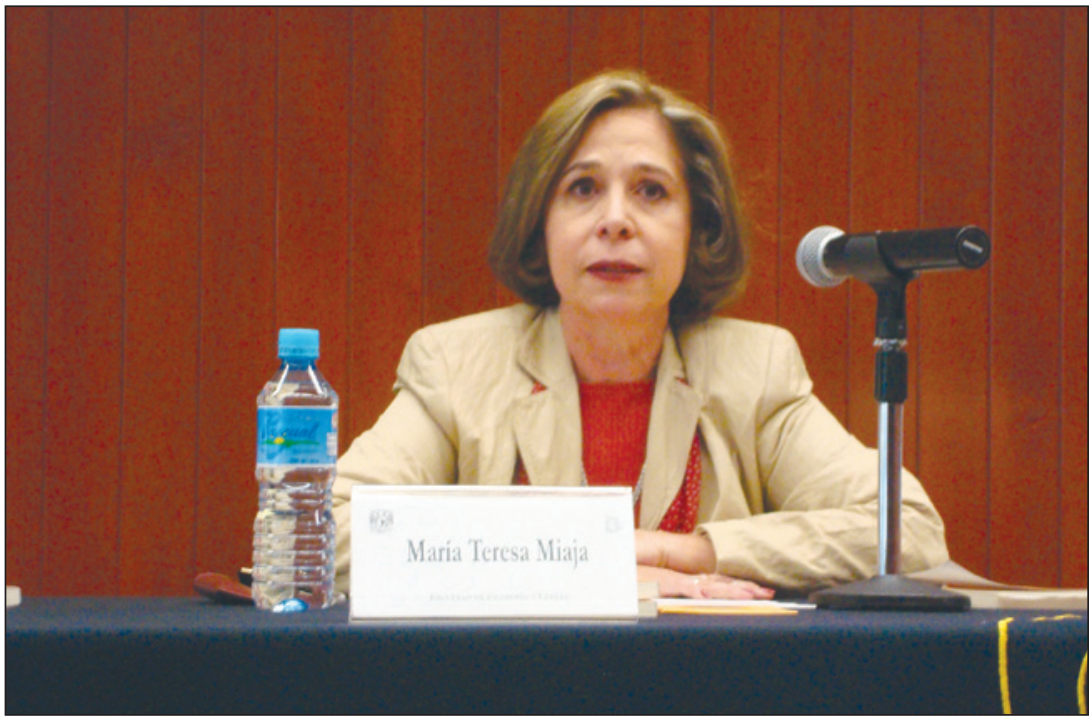

María Teresa Miaja

Caudet, Francisco. El exilio republicano en México. Las revistas literarias (1939-1971), Madrid: Fundación Banco Exterior, 1992.

Caudet, Francisco. El exilio republicano de 1939, Madrid: Cátedra, 2005.

Cerrillo, Pedro C. y Miaja, Ma Teresa (coords). La literatura infantil y juvenil española en el exilio mexicano, San Luis Potosí: El Colegio de San Luis, 2013.

Cerrillo, Pedro C. y Sánchez Ortiz, César. «Literatura con mayúsculas», Ocnos, 2, 2006: 7-22.

Cruz Orozco, José I. «Vida y obra de un maestro freinetista. El caso de Patricio Redondo». Juan A. Díaz (coord.), Castellanos sin Mancha. Exiliados CastellanoManchegos tras la Guerra Civil, Madrid: Celeste Ediciones, 1999: 43-52.

Franco, Marie. «Para que lean los niños: II República y promoción de la literatura infantil». Jean M. Desvois (coord.), Prensa, impresos, lectura en el mundo hispánico contemporáneo. Homenaje a Jean F. Botrel, Burdeos, Universidad de Burdeos, 2005: 251-272.

García Padrino, Jaime. Libros y literatura para niños en la España contemporánea, Madrid: Pirámide, 1992.

García Padrino, Jaime. «Primeros clásicos de nuestra literatura infantil y juvenil (1931-1936)». Pedro C. Cerrillo y Carlos Martínez Soria (coords.), Carlos, Lectura, infancia y escuela. 25 años de libro escolar en España: 1931-1956, Cuenca: Ediciones de la UCLM, 1999: 59-67.
Literatura infantil y educación en el exilio español en México

PEDRO C. CERRILLO 
Hernández Díaz, José $M^{a}$. «Maestros, inspectores y pedagogos en el exilio español de 1939». José $M^{a}$ Balcells, José $\mathrm{M}^{\mathrm{a}}$ y José A. Pérez Bowie (eds.), El exilio cultural de la Guerra Civil, 19361939. [En línea] http://213.0.4.19//servlet/ SirveObras/01349497566571272199680/ p0000002.htm. Consultado el 15 de enero de 2011.

Jarnés, Benjamín. El libro de oro de los niños, México, D.F.: Acrópolis, 6 vols., 1943.

Jiménez Mier y Terán. «El exilio de un maestro: José de Tapia». Claudio Lozano (ed.), 1939, el exilio pedagógico, Barcelona: Cooperativa Universitaria Sant Jordi, 1999: 57-82.

Llorens, Ramón. «Prólogo» al facsimilar El bloqueo del castillo de Catapún, de Magda Donato, Cuenca: Ediciones de la UCLM y CEPLI, 2011: 7-14.

Ruiz-Funes, Concepción. «Maestros y alumnos del exilio español republicano en
México». Claudio Lozano (ed.), 1939, el exilio pedagógico. Estudios sobre el exilios pedagógico republicano español de 1939, Barcelona: PPU, 1999: 39-55.

Sánchez Ortiz, C. y Cerrillo, Pedro C. «Literatura Infantil y Juvenil en la guerra civil española». Pedro C. Cerrillo y Carlos J. Martínez (eds.), Lectura, infancia y escuela. 25 años de libro escolar en España: 1931-1956, cit., 2009: 85-97.

Sánchez Trincado, José L. y Olivares Figueroa, R. Poesía infantil recitable, Madrid: Aguilar, edición facsimilar de 1935, Madrid: Compañía Literaria, 1994.

Sotomayor, $\mathrm{M}^{\mathrm{a}}$ Victoria. «La literatura infantil española de posguerra (1939-1956)». Pedro C. Cerrillo y Carlos J. Martínez, cit., 2009: 113-124.

Fecha de recepción: 24/04/2015

Fecha de aceptación: 15/09/2015 